\title{
A Study on the Quality Management of Low-cost Accommodation
}

\author{
Nan-Young Kim1), Hyung-Ji Chang2)
}

\begin{abstract}
The present study is aimed at investigating the quality management of low-cost accommodation. At first, it was investigated to what level of improvement customers believe is necessary for factors affecting the quality of the low-cost lodging industry. Second, the need for improvement for key factors was explored for differences in general requirements. The collected data were reviewed by descriptive analysis, factor analysis, reliability analysis, and different analysis(t-test and ANOVA). As a result, the study found the low-cost accommodation quality factors are divided into three factors which are cleanliness'safety quality, information quality, and human-external quality, and the three factors have been partially verified for significant differences depending on general matters. Based on these findings, the following implications were presented. All three quality factors, which are cleanliness·safety quality, information quality and human external quality, need to be improved. In particular, it is necessary for women and customers in their 20 s to emphasize cleanliness safety quality, and for 20 s and those with high visit rates, marketing to emphasize information quality is necessary.
\end{abstract}

Keywords: Low-cost Accommodation, Quality Management, Customer Need, Lodging Industry

\section{Introduction}

The number of international tourists, which continues to increase with globalization, is predicted to reach 1.8 billion by 2030[1]. Even if there are changes due to inbound tourism, outbound and domestic tourists have increased. The tourism industry has attracted attention as an important strategic industry for the national economy[2].

However, Korea's tourism industry is demanding an improvement in the nature of the tourism industry due to the growth of the low-cost inbound tourism market, which is biased toward China and Japan, and the outbound tourism market which favors overseas tourism over domestic tourism. It is necessary to strengthen internal competitiveness through qualitative growth rather than quantitative growth of the tourism industry. In particular, the importance of

Received(May 23, 2020), Review Result(1st: July 13, 2020, 2nd: August 31, 2020), Accepted(September 25, 2020)

1) (Associate Professor) 31460 Dept. Global Tourism, Sunmoon Univ., Tangjeong-myeon, Asan-si, Chungcheongnam-do, Korea

email: kyoung52@sunmoon.ac.kr

2) (Associate Professor, Corresponding Author) 31460 Dept. Global Tourism, Sunmoon Univ., Tangjeong-myeon, Asan-si, Chungcheongnam-do, Korea

email: maria07@sunmoon.ac.kr 
the quality of the lodging industry is emphasized based on the proportion of lodging tour accounting for more than $73 \%$ of the number of tour days[3].

In terms of price, the lodging industry provides differentiated services according to the price range from high to low and the industry that more people can use for the public is low-cost accommodation. However, it is true that quality control is not easy for low-cost accommodation compared to expensive ones. Therefore, it is necessary to manage the quality so that tourists using low-cost accommodation can make more reliable choices[4].

The present study investigates the factors affecting the quality of low-cost accommodation and the level of improvement that actual customers consider to be necessary for the major factor. The study examines whether there is a difference in the degree of improvement demand for factors derived from general matters. This study is intended to provide useful information in developing practical strategies to improve the quality of the low-cost accommodation.

\section{Theoretical Reviews}

\subsection{Tourism and Accommodation Quality}

The qualitative development of tourism is possible through the high value-added tourism industry. The provision of the highest level of hospitality services and continuous systematic quality management are the basis for improving tourism competitiveness at the international level[5]. The level of tourism quality is determined by the difference between the level that tourists expected for tourism products and services that they actually experienced[6]. Quality management of tourism is important because satisfaction and dissatisfaction with tourism products and services perceived as such will have a positive or negative effect on tourist behaviors. The quality management level of Korea's tourism can be measured through the World Economic Forum (WEF)'s Travel \& Tourism Competitiveness Index (TTCI), which ranked 16th out of 140 countries as of 2019[7]. This indicates that tourism competitiveness is inferior compared to the evaluation and growth level of Japan and China. It is shown that tourism quality improvement is necessary to secure a relative advantage with major tourism competitors. In particular, the tourism service infrastructure, including the accommodation industry, ranked 23rd, indicating that it is a field that requires more care and management than other tourism evaluation fields. Moreover, complaints of tourists, which are adversely affecting the quality management of Korean tourism, can be confirmed by a tourism complaint report. As of 2019, the largest number of tourists reporting complaints about Korean tourism was from China 
(39\%), followed by Japan (22.1\%) and Korea (13.3\%). Regarding the number of complaints, shopping was the largest with $27.9 \%$ of the total complaints, followed by taxis at $16.7 \%$, and accommodation at $13.3 \%$. Specific inconveniences related to the accommodation include poor personal service $29 \%$, poor facility and hygiene management $20 \%$, cancellation and penalty $16.1 \%$, failure to fulfill reservation conditions and false advertisement $7.1 \%$, collection of excessive charges 5.2\%, and theft and loss 1.9\%[8]. It was found that tourists responded most sensitively to software-based human services when booking the accommodation, which is a result of indicating how important the role of employees is to improve organizational performance[9]. Then, in the basic management at the hardware level, it was found that they were dissatisfied with the customer variables. In order to solve those problems, the same management effect as for the franchise system is required[10]. Furthermore, an alternative method of improving efficiency is requested through advertising and publicity as well as improving management of dissatisfaction factors[11].

\subsection{Accommodation Quality Management}

The lodging industry can be classified with various criteria including the Tourism Promotion Act and the Public Health Management Act on a legal basis. The Tourism Promotion Act is divided into the hotel business and the resort condominium businesses. The Public Health Management Act is divided into general and living lodging businesses. The low-cost accommodation examined in this study corresponds to the general lodging business. It is a form of business that provides services such as facilities for guests to sleep and stay in. In general, it is considered similar to a budget hotel, a low-cost accommodation, which is centered on basic room service.

Quality management of the accommodation has been carried out through certification systems based on local governments and government agencies. Various systems are in operation for the certification of the lodging industry. The hotel industry rating system is supervised by the Korea Tourism Organization, while the Korea Tourism Quality Certification System is representative of mid- and low-cost accommodations. The hotel industry rating system is operated for the tourist hotel business, Korean traditional hotel business, family hotel business, small hotel business, medical tourism hotel business, and water tourism hotel business. It is a system introduced since 1971 to provide information. Prior to 1999, the government carried out this project directly, but after 1999, it was operated through private consignment. Since 2015, the Korea Tourism Organization has commissioned the rating service to improve the fairness and 
reliability of hotel ratings. Hotel industry grades are largely divided into grades 1 to 5 , and the grades are classified by gender marks, and a signboard is attached at the entrance of the hotel[12].

Compared to the hotel industry, it is difficult to establish a brand image or provide standardized and differentiated services for the low-cost accommodation with building customer loyalty. Thus, it is necessary to present a management method that allows low-cost accommodations to maximize quality by utilizing limited resources and manpower[4]. Representative certification systems for low-cost accommodation businesses include the Goodstay system of the Korea Tourism Organization and the Ministry of Health and Welfare. In addition, Greentel in Daegu, clean and low-cost accommodations in Busan, Poenbitel in Haeundae, and Michu Hall Stay in Incheon were operated. However, the problems such as inefficiency of the certification system operation, lack of professionalism and publicity effect due to the similar certification systems increased the need for developing an integrated certification system[13].

Leading countries in the tourism industry are operating a quality certification system to manage quality of accommodation. Examples include Quality Tourism Services in Hong Kong, Qualmark in New Zealand, Calidad Turistica in Spain, Qualite Tourisme in France, and Quality in Tourism in the UK, and most of them are given certification marks and quality management by separate organizations with expertise. These systems are being implemented to provide reliable information to tourists and to induce tourism companies to provide high-quality tourism services[14]. Korea also has such an integrated certification system. It is being implemented for major contact convenience facilities in the tourism industry, such as shopping, and plans to expand its scope in the future. Accommodation certification targets are being used on a more popular level, but more focused on low-cost accommodation businesses that have difficulty in quality control, specifically targeting general and daily living accommodation, foreign tourist city private residences, and Hanok stay businesses[15].

In the case of motels, which are the representative facilities of low-cost accommodation, it is essential to meet several criteria to get certified, which include cleanliness standards, openness of information desks, non-installation of closed structures in parking lots, non-operation of rooms, restrictions on adult broadcasting, and posting of room rates at the front desk. Based on these evaluation criteria, the accommodation industry is subjected to on-site evaluation. When the criteria pass the on-site evaluation of the accommodation industry, they will meet the essential requirements. If a score of $70 \%$ or more of the total score is reported through the first and second on-site evaluation, the standard certification will be granted. If the businesses 
score more than $90 \%$ of the total score, they will be awarded Premier level certification[16]. In this study, the evaluation criteria of the Korea Tourism Quality Certification System were used as a factor affecting the quality of the low-cost accommodation industry.

\section{Research Method}

\subsection{Research Design and Method}

The questionnaire of this study consisted of two categories: factors for evaluating the quality of low-cost accommodation and customer variables. The quality evaluation criteria of the low-cost accommodation consisted of 20 questions based on the general accommodation industry evaluation criteria of the Korea Tourism Quality Certification System and 20 questions were selected through careful review by the relevant experts[16]. The measurement for each item was based on a 5-point Likert scale (1 point-no improvement at all, 5 points-high need for improvement). For the demographical variables of participants, it consisted of 5 questions; gender, age, occupation, main purpose of use within one year, and number of uses within one year. Each of these items was measured on a nominal scale.

The participants of this study were adult men and women who have experienced using low-cost accommodation centered on motels within the past year. In addition, the survey was conducted by the Embrain online research institute, which has the largest research panel in Korea. The purpose of the survey and the content of the questionnaire were fully understood and notified in advance so that participants could respond to the questionnaire, then, it was distributed and collected. A total of 228 questionnaires were collected and used for analysis. The SPSS 21 was used for the analysis, and factor and reliability analysis were performed to secure validity and reliability. In addition, $t$-test and ANOVA were conducted to analyze customer demand for derivation factors.

\subsection{Characteristics of Sample and Low-cost Accommodation Use}

First, the participants included 113 males (49.6\%) and 115 females (50.4\%). Second, the age was $58(25.4 \%)$ over 50, and 57 (25) each in their 40s and 20s. \%), and 56 people were in their 30s (24.6\%). Third, the participants' occupations included management and office workers 106 $(46.5 \%)$, civil servants and professional workers $32(14 \%)$, housewives 18 (7.9\%), self-employed $17(7.5 \%)$, students $15(6.6 \%)$, services and one salesperson (5.3\%), 12 manufacturing and 
technical workers $(5.3 \%)$, and 16 others $(7 \%)$.

The main objectives of using low-cost accommodation within the past year were $193(84.6 \%)$ leisure tourism activities and $35(15.4 \%)$ business trips. In addition, in the past year, the number of uses of the low-cost accommodation business was 1 to 2 times for 44 people $(19.3 \%), 3$ to 4 times for 64 people (28.1\%), 5 to 6 times for 42 people $(18.4 \%)$, and 7 or more times 78 people $(34.2 \%)$. In other words, most of the low-cost accommodation was used for leisure tourism purposes, and more than half of them used it five or more times within the year.

\section{Findings}

\subsection{The Results of Factor and Reliability Analysis}

As a result of conducting factor and reliability analysis, three factors were largely derived as shown in [Table 1]. They are named as the cleanliness and safety quality factor, information quality factor, and human and external quality factor, taking into account the characteristics of the constituent variables. Three variables, adult broadcasting control device, the closure of the front reception space, and the installation of a closed barrier in the parking lot that hinder the validity and reliability were removed in the analysis. To meet the customer's demand for improvement by each factor, all three factors showed the above average level of improvement demand, and the demand for improvement on cleanliness-safety quality factors was the highest, followed by improvement in information quality factors, and human external quality factors.

[Table 1] The Result of Analysis of Factor and Reliability of Low-cost Accommodation Quality

\begin{tabular}{|c|c|c|c|c|c|c|}
\hline \multirow{4}{*}{ Factor } & Variables & $\begin{array}{c}\text { Standard } \\
\text { factor } \\
\text { lodging }\end{array}$ & $\begin{array}{c}\text { Eigen } \\
\text { value }\end{array}$ & $\begin{array}{c}\text { Proportion } \\
\text { variance } \\
\text { explained } \\
(\%)\end{array}$ & $\begin{array}{c}\text { Cronbach' } \\
\mathrm{s} \\
a\end{array}$ & Mean \\
\hline \multirow{5}{*}{$\begin{array}{c}\text { Cleanliness } \\
\text { safety } \\
\text { quality }\end{array}$} & Overall cleanliness & .833 & 5.858 & 32.543 & .953 & 3.395 \\
\hline & Bathroom facilities quality and cleanliness & .815 & & & & \\
\cline { 2 - 7 } & Bed and bedding quality and cleanliness & .815 & & & & \\
\cline { 2 - 7 } & Room and bathroom amenities and quality & .793 & & & & \\
\cline { 2 - 7 } & Quality of room facilities & .757 & & & & \\
\cline { 2 - 7 } & Management and cleanliness of common & .645 & & & & \\
\cline { 2 - 7 } & facilities such as corridors and stairs & & & & & \\
\cline { 2 - 7 } & Safety and security device status in the room & .590 & & & & \\
\hline
\end{tabular}




\begin{tabular}{|c|c|c|c|c|c|c|}
\hline & $\begin{array}{c}\text { Fire and safety conditions of accommodation } \\
\text { facilities }\end{array}$ & .519 & & & & \\
\hline \multirow{4}{*}{$\begin{array}{c}\text { Information } \\
\text { quality }\end{array}$} & $\begin{array}{c}\text { Provision of information such as change of } \\
\text { accommodation reservation, cancellation, and } \\
\text { refund policy }\end{array}$ & .780 & 3.965 & 22.030 & .890 & 3.349 \\
\hline & $\begin{array}{l}\text { Provision of information related to the use of } \\
\text { accommodation facilities }\end{array}$ & .777 & & & & \\
\hline & $\begin{array}{l}\text { No notice of part-time fees at the information } \\
\text { desk }\end{array}$ & .723 & & & & \\
\hline & Posting plans in the information desk & .670 & & & & \\
\hline \multirow{4}{*}{$\begin{array}{l}\text { Human } \\
\text {-external } \\
\text { quality }\end{array}$} & $\begin{array}{c}\text { The state of dress and appearance of the } \\
\text { worker }\end{array}$ & .865 & 3.146 & 17.479 & .866 & 3.322 \\
\hline & Professional expertise and level of service & .777 & & & & \\
\hline & Building exterior and management status & .665 & & & & \\
\hline & Lobby comfort & .528 & & & & \\
\hline \multicolumn{7}{|c|}{$\mathrm{KMO}=.953$ Bartlett's test $=3554.536 \quad(p=.000)$} \\
\hline
\end{tabular}

\subsection{The Result of Different Analysis of Quality Factor}

As a result of analyzing whether there is a difference in the quality evaluation factors of the low-cost accommodation industry in accordance with customer variables, there was no significant difference in the purpose of use and occupation, while there was a significant difference in gender, age, and number of uses. Focusing on the results from the types of significant differences, they are as follows. First, in terms of gender, as shown in [Table 2], there was a difference in the degree of improvement demand for quality factors. Specifically, it was found that female customers had higher demands for improvement in terms of cleanliness. safety quality factors than males.

[Table 2] The Result of Difference Analysis on Gender

\begin{tabular}{|c|c|c|c|}
\hline Gender & $\begin{array}{c}\text { Cleanliness safety } \\
\text { quality }\end{array}$ & $\begin{array}{c}\text { Information } \\
\text { quality }\end{array}$ & $\begin{array}{c}\text { Human external } \\
\text { quality }\end{array}$ \\
\hline Female & 3.5072 & 3.3891 & 3.3478 \\
\hline Male & 3.2802 & 3.3075 & 3.2965 \\
\hline- & $t=1.886 \quad p=.061^{*}$ & $t=649 \quad p=517$ & $t=.453 \quad p=.651$ \\
\hline
\end{tabular}

${ }^{*} p<.10$

Second, as suggested in [Table 3], there was a significant difference in quality factors in accordance with customer age. With regard to cleanliness'safety quality factors and information quality factors, the improvement demands were relatively high in 20 s. 
[Table 3] The Results of Difference Analysis on Age

\begin{tabular}{|c|c|c|c|}
\hline Ages & $\begin{array}{c}\text { Cleanliness'safety } \\
\text { quality }\end{array}$ & $\begin{array}{c}\text { Information } \\
\text { quality }\end{array}$ & $\begin{array}{c}\text { Human'external } \\
\text { quality }\end{array}$ \\
\hline $20 \mathrm{~s}$ & 3.7427 & 3.6140 & 3.5000 \\
\hline $30 \mathrm{~s}$ & 3.3393 & 3.2366 & 3.1920 \\
\hline $40 \mathrm{~s}$ & 3.2203 & 3.3158 & 3.2982 \\
\hline over $50 \mathrm{~s}$ & 3.2778 & 3.2284 & 3.2974 \\
\hline- & $F=9.576 \quad p=.005^{* * *}$ & $F=3.332 \quad p^{F} .054^{*}$ & $F=.722 \quad p^{*} .321$ \\
\hline
\end{tabular}

${ }^{* * *} p<.01{ }^{*} p<.10$

Third, as shown in [Table 4], there was a significant difference in the quality factor in accordance with the number of uses of the low-cost accommodation business. Specifically, the higher the number of uses of the low-cost accommodation, the higher the demand for improvement on the information quality factor.

[Table 4] The Results of Difference Analysis on Visits

\begin{tabular}{|c|c|c|c|}
\hline Visits & Cleanliness safety quality & $\begin{array}{c}\text { Information } \\
\text { quality }\end{array}$ & $\begin{array}{c}\text { Human external } \\
\text { quality }\end{array}$ \\
\hline 1-2 times & 3.2348 & 3.1023 & 3.2102 \\
\hline 3-4 times & 3.4497 & 3.3750 & 3.3242 \\
\hline 5-6 times & 3.4815 & 3.3750 & 3.4702 \\
\hline over 7 times & 3.3932 & 3.4519 & 3.3045 \\
\hline- & $F=.715 \quad p=.358$ & $F=3.062 p=.066^{*}$ & $F=.512 p F .405$ \\
\hline
\end{tabular}

${ }^{*} \mathrm{p}<.10$

\section{Conclusion and Implication}

The present study verified the factors affecting the quality management of low-cost accommodation and improvement needs were investigated on actual tourists. Based on the result, three factors affecting the quality of the low-cost accommodation industry were cleanliness·safety quality, information quality, and human'external quality. In addition, the three quality factors showed some significant differences depending on gender, age and the number of low-cost accommodation uses.

The findings point out the following. First, it is worth noting that low-cost accommodation customers demand an improvement in the above-average level for the three quality factors derived, and that the demand for improvement in cleanliness'safety quality factors is the highest. Therefore, efforts should be made for overall quality control, focusing on cleanliness-safety quality factors, to improve the competitiveness of low-cost accommodation businesses. Second, it is worth noting that variables that have been believed to be the most 
negative criteria for low-cost accommodation businesses have relatively lower demand for improvement than other variables and have not been derived as factors for quality evaluation. In other words, quality control is needed that focuses on factors that affect the quality judgment of actual customers, rather than the standards believed to be negative aspects of the low-cost accommodation industry. Third, it is worth noting that there is a high demand for improvement in women and 20 s for cleanliness-safety quality factors, and there is a high demand for improvement in customers with high utilization rates in their 20s for information quality factors. After all, marketing that emphasizes cleanliness-safety quality is necessary for women and younger generations, and more attention should be paid to information quality management for those in their 20s who are highly sensitive to information and state customers who have high utilization rates.

Based on these findings, the theoretical implications of this study are meaningful in that they provided a valid basis for the evaluation criteria for the quality control of the low-cost accommodation industry, which was lacking in research. Also, the results of this study is significant such that it can provide useful information to working-level managers so that quality control can be carried out based on items that tourists require improvement.

On the other hand, this study has several limitations. First, the results cannot be generalized across South Korea. The study focused on tourists who use motels among various types of low-cost accommodation and only uses online panels. Therefore, in future studies, it is necessary to examine more diverse types of low-cost accommodation and to expand survey participants through various channels. Furthermore, the research is needed to judge more practical performance factors through investigation of the impact relationship between the quality factors and outcome factors of the low-cost accommodation industry.

\section{References}

[1] UNWTO, International Tourism Results 2018 and Outlook 2019, https://webunwto.s3-eu-west-1. amazonaws.com/imported_images/51589/unwto_barometer_jan19_presentation_en.pdf, Oct 31 (2019)

[2] Ministry of Culture, Sports and Tourism, 2018 Annual Report on Tourism Trends, https://www.mcst.go.kr/kor/s_policy/dept/deptView.jsp?pSeq=1756\&pDataCD=0406000000\&pType, $\quad$ Oct 31 (2019)

[3] Ministry of Culture, Sports and Tourism, 2018 Korea National Tourism Survey, https://www.mcst.go.kr/kor/s_notice/press/pressView.jsp?pSeq=17379, Oct 31 (2019) 
[4] S. H. Kim, K. S. Kim, A Study on the Effects of Tangible-Intangible Service Quality of the Small and Medium Lodging Industry on Overall Service Quality Perception, International Journal of Tourism and Hospitality Research, (2011), Vol.25, No.4, pp.103-121.

[5] H. S. Oh, H. J. Kim, Quality Control for Qualitative Evolution of Korean Tourism, Korea: Korea Culture \& Tourism Institute, http://www.yes24.com/Product/Goods/94224323, Oct 31 (2013)

[6] R. Black, A, Crabtee, Quality Assurance and Certification in Ecotourism, Australia: Cabi Publishing Wallingford, (2007)

[7] WEF, The Travel \& Tourism Competitiveness Report, https://www.weforum.org/reports/the-traveltourism-competitiveness-report-2019, Oct 31, (2019)

[8] Korea Tourism Organization, Comprehensive Analysis Report on Tourist Complaint, http:/grta.co.kr/board/download/tour/244/file/1/327/b05821506761bdc24a1742df2256c735/2595e26cb9daafcaa75fec 043cbcc4482695edf8, May 17 (2021).

[9] J. N. G. Srinivas, K. L. Priyanka, I. H. Jang, P. Cheng, A Study on Role of Employee Engagement and its Effectiveness on Organizational Performance, International Journal of Business Policy and Strategy Management, (2017), Vol.4, No.2, pp.1-8.

[10] H. C. Yang, H. Y. Cho, S. H. Han, Effects of Franchise Management Styles on Task-focused Conflicts, Procedural Conflicts and Dissolution Intention, International Journal of Business Policy and Strategy Management, (2016), Vol.3. No.1, pp.47-52.

[11] J. Y. Sung, The Effectiveness of Advertisement after Consumer Dissatisfaction, International Journal of IT-based Business Strategy and Management, (2016), Vol.2, No.1, pp.51-56.

[12] Korea Hotel Rating Homepage, https://www.hotelrating.or.kr/main.do, May 20 (2020)

[13] Korea Consumer Agency, Survey on the Actual Condition of Consumer Problems on Accommodation Services: Focused on Certified Accommodations by the Korea Tourism Organization, https://www.kca.go.kr/home/board/download.do?menukey=4062\&fno=10023093\&bid=00000146\&did=1002758914 , May 31 (2018)

[14] M. S. Kang, Integrated Quality Certification System of the Tourism Industry, Korea Legislation Research Institute, https://kto.visitkorea.or.kr/kor/biz/marketing/qual.kto, Aug 10 (2017)

[15] Korea Tourism Organization, Implementation of the Quality Certification System for Korean Tourism Quality, https://www.mcst.go.kr/kor/s_notice/press/pressView.jsp?pSeq=16179, Aug 10 (2019)

[16] Korea Tourism Organization, 2019 Manual for Evaluation of Korea Quality Certification System, https://koreaquality.visitkorea.or.kr/qualityIntroduction/screeningManual.kto, Aug 10 (2019) 